\title{
Long-term outcomes after surgery for catastrophic epilepsy in infants: institutional experience and review of the literature
}

\author{
Vincent C. Ye, MD, ${ }^{1}$ Ashish H. Shah, MD, ${ }^{2}$ Samir Sur, MD, ${ }^{2}$ Justin K. Achua, MS, ${ }^{2}$ \\ Shelly Wang, MD, MPH, ${ }^{3}$ George M. Ibrahim, MD, PhD, ${ }^{1}$ Sanjiv Bhatia, MD, ${ }^{3}$ and \\ John Ragheb, MD2,3 \\ 1 Division of Neurosurgery, Department of Surgery, Hospital for Sick Children, University of Toronto, Ontario, Canada; \\ 2Department of Neurosurgery, University of Miami; and 'Division of Neurosurgery, Nicklaus Children's Hospital, Miami, Florida
}

\begin{abstract}
OBJECTIVE Uncontrolled epilepsy is associated with serious deleterious effects on the neurological development of infants and has been described as "catastrophic epilepsy." Recently, there has been increased emphasis on early surgical interventions to preserve or rescue neurodevelopmental outcomes in infants with early intractable epilepsy. The enthusiasm for early treatments is often tempered by concerns regarding the morbidity of neurosurgical procedures in very young patients. Here, the authors report outcomes following the surgical management of infants (younger than 1 year).

METHODS The authors performed a retrospective review of patients younger than 1 year of age who underwent surgery for epilepsy at Miami (Nicklaus) Children's Hospital and Jackson Memorial Hospital between 1994 and 2018. Patient demographics, including the type of interventions, were recorded. Seizure outcomes (at last follow-up and at 1 year postoperatively) as well as complications are reported.

RESULTS Thirty-eight infants (median age 5.9 months) underwent a spectrum of surgical interventions, including hemispherectomy $(n=17)$, focal resection $(n=13)$, and multilobe resections $(n=8)$, with a mean follow-up duration of 9.1 years. Hemimegalencephaly and cortical dysplasia were the most commonly encountered pathologies. Surgery for catastrophic epilepsy resulted in complete resolution of seizures in $68 \%(n=26)$ of patients, and $76 \%(n=29)$ had a greater than $90 \%$ reduction in seizure frequency. Overall mortality and morbidity were $0 \%$ and $10 \%$, respectively. The latter included infections $(n=2)$, infarct $(n=1)$, and immediate reoperation for seizures $(n=1)$.
\end{abstract}

CONCLUSIONS Surgical intervention for catastrophic epilepsy in infants remains safe, efficacious, and durable. The authors' work provides the longest follow-up of such a series on infants to date and compares favorably with previously published series.

https://thejns.org/doi/abs/10.3171/2020.1.PEDS19537

KEYWORDS infant; epilepsy; surgery; outcomes; hemispherectomy

$\mathrm{S}$ EIZURE disorders in childhood can either follow a benign and relatively inconsequential course or have significant deleterious effects on neurocognitive development. These latter epilepsies are so-called catastrophic. ${ }^{1-4}$ Despite maximal medical management, a significant number of infants (roughly 25\%) continue to progress with seizures. ${ }^{5-8}$ The considerable adverse effects of unrelenting seizure activity on the developing brain result in cognitive, psychological, and functional impairment and have been associated with up to a $20 \%$ risk of mortality in some series. ${ }^{79}$

Epilepsy surgery has played an important role in the treatment of patients affected by medically intractable seizures, resulting in excellent seizure control and improvement in quality in life in a greater number of patients with hemispheric epileptogenic conditions. ${ }^{710-15}$ In cases of catastrophic epilepsy, it has been suggested that neurosurgical treatment can alter the natural history of the disease

ABBREVIATIONS $D Q=$ developmental quotient.

SUBMITTED September 14, 2019. ACCEPTED January 28, 2020.

INCLUDE WHEN CITING Published online April 24, 2020; DOI: 10.3171/2020.1.PEDS19537. 
and that surgery should be offered to reduce the impact of the seizures on the developing brain as soon as technically feasible. ${ }^{7,10,16-19}$ Bolstered by technological innovations and advances in surgical techniques, there has been a growing trend toward surgically treating medically refractory epilepsy in very young children., ${ }^{3,10,18,20,21}$ Reasons for deferring surgery in young children have included technical challenges, a presumed risk of increased complications thought to relate to the child's limited blood volume, and the immaturity of the brain and developing myelination patterns. ${ }^{17,22-24}$ The literature surrounding treatment of these patients is largely composed of small case reports and retrospective case series that have indicated that epilepsy surgery in infants and young children is effective and relatively safe and can result in improved developmental outcomes. ${ }^{10,16,25-32}$

Here, we present a retrospective series of 38 infants younger than 1 year who underwent surgery at a single program encompassing 2 sites, with long-term follow-up approaching 10 years. We report results such as Engel classification at last follow-up, seizure freedom or reduction posttreatment, and morbidity and mortality. In addition, we conducted a comprehensive and updated literature review on outcomes after epilepsy surgery in infants and young children operated on before the age of 3 years, with a focus on surgical and developmental outcomes, and morbidity and mortality rates. While literature reviews on epilepsy in young children exist, ${ }^{28,31}$ we include a particular focus on data regarding infants.

\section{Methods}

\section{Patient Selection}

After receiving institutional review board approval, we reviewed the patient charts of infants $(<12$ months $)$ from Nicklaus (Miami) Children's Hospital and Jackson Memorial Hospital between December 1994 and October 2018. We performed a retrospective review of patients who presented with infantile seizures that impacted early development and who underwent surgery. All patients were discussed at a multidisciplinary epilepsy conference comprising neurologists, neuropsychologists, and the 2 senior surgeons. Infants selected for surgery were thought to have a good probability of improved seizure outcomes as a result of phase 1 investigations (i.e., video telemetry and MR). Extended EEG and MRI were the primary modes of investigation (prior to invasive monitoring). No phase 2 investigations (i.e., invasive monitoring) were conducted on these patients, as they were only selected for surgery with good correlation from phase 1 tests.

\section{Data Collection}

Patient demographics, including current age and sex, and relevant clinicoradiographic information, including diagnosis, age at onset of epilepsy, date of surgery, type of surgical procedure, complications, postoperative seizure frequency, duration of the seizure-free period, date of last follow-up, and Engel class, were collected. All patients in this study were treated with partial or complete hemispherectomy, lobectomy, or lesionectomy.

Postoperative seizure outcome at the 1-year postopera-
TABLE 1. Characteristics of 38 infants undergoing surgery for catastrophic epilepsy

\begin{tabular}{|c|c|}
\hline Patient Characteristic & Value \\
\hline \multicolumn{2}{|l|}{ Current age } \\
\hline Median & $17 \mathrm{yrs}$ \\
\hline Mean (range) & 16 yrs \& 8 mos $(7-23$ yrs \\
\hline \multicolumn{2}{|l|}{ Sex, $n(\%)$} \\
\hline Male & $25(65.8)$ \\
\hline Female & $13(34.2)$ \\
\hline \multicolumn{2}{|l|}{ Age at epilepsy onset } \\
\hline Median & 11.3 days \\
\hline Mean (range) & 46.5 days ( $0-317.6$ days) \\
\hline \multicolumn{2}{|l|}{ Age at 1st op } \\
\hline Median & $5.9 \mathrm{mos}$ \\
\hline Mean (range) & 5.9 mos (0.9-11.6 mos) \\
\hline \multicolumn{2}{|l|}{ Seizure-free duration } \\
\hline Median & $6.4 \mathrm{yrs}$ \\
\hline Mean (range) & 7.1 yrs (10 days-19.6 yrs) \\
\hline \multicolumn{2}{|c|}{ Engel class at last follow-up } \\
\hline Median & 1 \\
\hline Mean (range) & $1.8(1-4)$ \\
\hline \multicolumn{2}{|l|}{ Follow-up duration } \\
\hline Median & $7.8 \mathrm{yrs}$ \\
\hline Mean (range) & 9.1 yrs (2 mos-22.3 yrs) \\
\hline
\end{tabular}

tive mark and duration of the seizure results were the primary outcomes. Seizure freedom was determined to be an absence of any type of seizure after the date of surgery. For the patients with follow-up data available beyond the 1-year postoperative mark, the duration of seizure freedom was defined as either the time between the surgical date and the next subsequent seizure or the time between the surgical date and the most recent follow-up if they remained seizure free. Secondary outcomes included survival rates and postoperative complications.

\section{Statistical Analysis}

Results are described as frequencies and percentages. Prism 7 (GraphPad Software) was used for Kaplan-Meier curve production and statistical analysis.

\section{Literature Review}

Databases including PubMed and MEDLINE were used for literature search. MeSH terms used in the search included "Epilepsy/di, pa, su" (diagnosis, pathology, surgery), "treatment outcome," and "infant." The search was limited to English-language articles with full-text availability from 1990 to April 2019. Citations from key articles were cross-referenced for completeness. Articles were included in our literature review if they included at least 10 cases in which an infant was operated on before the age of 3 years, with functional outcomes that could be correlated. For example, case series that had an age range of $0.5-5$ years at time of operation were not included if the functional outcomes of those operated on before the age of 3 
TABLE 2. Diagnosis, types of surgical procedures, and seizure outcomes

\begin{tabular}{|c|c|}
\hline Patient Characteristic & No. of Patients (\%) \\
\hline \multicolumn{2}{|l|}{ Diagnosis } \\
\hline Cortical dysplasia & $12(31.5)$ \\
\hline Hemimegalencephaly & $11(28.9)$ \\
\hline Tuberous sclerosis & $5(13.2)$ \\
\hline Infarction & $3(7.9)$ \\
\hline Ohtahara syndrome & $1(2.6)$ \\
\hline Rasmussen's encephalitis & $1(2.6)$ \\
\hline Neurocutaneous melanosis & $1(2.6)$ \\
\hline Tumor & $4(10.5)$ \\
\hline Temporal astrocytoma & $1(2.6)$ \\
\hline Hemispheric astrocytoma & $1(2.6)$ \\
\hline Poorly differentiated glioma & $1(2.6)$ \\
\hline Pleomorphic xanthoastrocytoma & $1(2.6)$ \\
\hline \multicolumn{2}{|l|}{ Resection type } \\
\hline Focal resection & $13(34.2)$ \\
\hline TLR & $7(18.4)$ \\
\hline FLR & $5(13.2)$ \\
\hline OLR & $1(2.6)$ \\
\hline MLR & $8(21.1)$ \\
\hline Hemispherectomy & $17(44.7)$ \\
\hline \multicolumn{2}{|l|}{ Seizure frequency at $1 \mathrm{yr}$ postop } \\
\hline Seizure freedom & $26(68.4)$ \\
\hline$>90 \%$ reduction & $3(7.9)$ \\
\hline$>50-90 \%$ reduction & $2(5.3)$ \\
\hline$<50 \%$ reduction & $7(18.4)$ \\
\hline
\end{tabular}

$\mathrm{FLR}=$ frontal lobe resection; $\mathrm{MLR}=$ multilobe resection; $\mathrm{OLR}=$ occipital lobe resection; $T L R=$ temporal lobe resection. years were not clearly delineated. Additional data, including mean age at seizure onset, mean age at operation, diagnosis/pathology, surgical technique, and complications, were extracted. Overall, 13 articles were included.

\section{Results}

Patient Demographics, Diagnosis, and Surgical Treatment

Thirty-eight children (25 males and 13 females) presented with early intractable catastrophic childhood epilepsy and underwent surgery at Miami Children's Hospital or Jackson Memorial Hospital and were included in this study (Table 1). Each patient included in the study experienced multiple seizures on a daily basis. The underlying diagnosis in this cohort included cortical dysplasia $(\mathrm{n}=12)$, hemimegalencephaly $(\mathrm{n}=11)$, and tumor $(\mathrm{n}=4)$ (Table 2). In the majority of patients, the onset of epilepsy was within the 1st month of life, with the median onset being 11.3 days (range 0-318 days). Thirty-three of the 38 children were followed up at least 4 years postoperatively, with a mean follow-up duration of 9.1 years (range 2 months-22.3 years). There were no patients in our study who underwent repeat resection.

The most common surgical procedures for this cohort of children with catastrophic epilepsy were hemispherectomy $(n=17)$ followed by focal resection $(n=13)$, with resection of the temporal lobe being the most common focal resection. Eight of the 38 children had multilobe resections, and all 11 children diagnosed with hemimegalencephaly underwent a hemispherectomy (Table 3 ). The median age at the time of surgery was 5.9 months (range 0.9-11.6 months). On average, 7 years of seizure freedom was achieved by surgery (range 10 days-19.6 years).

\section{One-Year Treatment Outcomes}

At the 1-year postoperative date, $26(68.4 \%)$ of the 38 children remained seizure free, while $3(7.9 \%)$ children experienced greater than $90 \%$ reduction in seizure fre-

TABLE 3. Diagnoses and types of surgical procedures

\begin{tabular}{|c|c|c|c|c|c|c|}
\hline & \multicolumn{4}{|c|}{ Focal Resection } & \multirow[b]{2}{*}{ Hemispherotomy } & \multirow[b]{2}{*}{ Total } \\
\hline & TLR & FLR & OLR & MLR & & \\
\hline Cortical dysplasia & 2 & 3 & 1 & 5 & 1 & $12(31.6)$ \\
\hline Hemimegalencephaly & & & & & 11 & $11(28.9)$ \\
\hline Tuberous sclerosis & 1 & 2 & & 2 & & $5(13.2)$ \\
\hline Infarction & & & & & 3 & $3(7.9)$ \\
\hline Ohtahara syndrome & & & & & 1 & $1(2.6)$ \\
\hline Rasmussen's encephalitis & & & & 1 & & $1(2.6)$ \\
\hline Neurocutaneous melanosis & 1 & & & & & $1(2.6)$ \\
\hline \multicolumn{7}{|l|}{ Tumor } \\
\hline Temporal astrocytoma & 1 & & & & & $1(2.6)$ \\
\hline Hemispheric astrocytoma & & & & & 1 & $1(2.6)$ \\
\hline Poorly differentiated glioma & 1 & & & & & $1(2.6)$ \\
\hline Pleomorphic xanthoastrocytoma & 1 & & & & & $1(2.6)$ \\
\hline Total & $7(18.4)$ & $5(13.2)$ & $1(2.6)$ & $8(21.1)$ & $17(44.7)$ & \\
\hline
\end{tabular}

Values represent the number of patients (\%). 

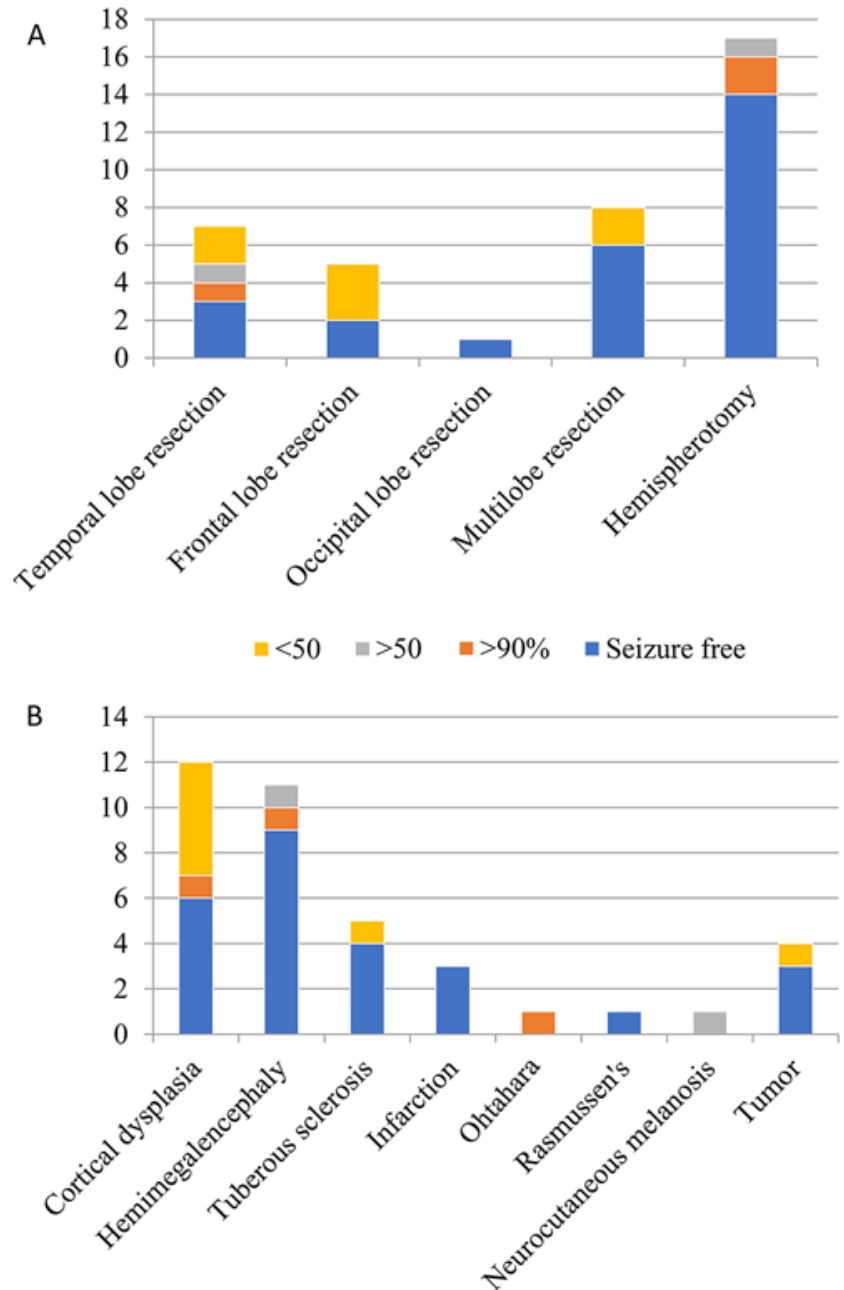

FIG. 1. A: One-year postoperative seizure outcomes based on surgical technique. B: One-year postoperative seizure outcomes based on surgical technique. Figure is available in color online only.

quency, and another 2 experienced a 50\%-90\% reduction. Seven (18.4\%) children experienced less than a 50\% reduction in seizure frequency (Table 2). Figure 1A shows the seizure-free outcomes at the 1-year mark based on surgical procedure: the hemispherectomy group had the best seizure outcome ( $n=14 / 17$ seizure free), followed by the multilobe resection group $(n=6 / 8$ seizure free) and the focal resection group ( $\mathrm{n}=7 / 13$ seizure free). In the focal resection group, the patient who underwent occipital lobe resection achieved seizure freedom at 1 year postoperatively. The temporal lobe resection and the frontal lobe resection group achieved $42.9 \%(\mathrm{n}=3 / 7)$ and $40 \%(\mathrm{n}=$ $2 / 5$ ) rates of seizure freedom, respectively.

With regard to pathologic correlation, the children diagnosed with stroke $(n=3)$ and Rasmussen's encephalitis $(\mathrm{n}=1)$ were all seizure free 1 year postoperatively. The hemimegalencephaly group had the next best seizure freedom rate at $81.8 \%(\mathrm{n}=9 / 11)$, followed by the tuberous sclerosis group at $80 \%(n=4 / 5)$. The corresponding numbers in the tumor group and in the cortical dysplasia group were $75 \%(n=3 / 4)$ and $50 \%(n=6 / 12)$, respectively. The

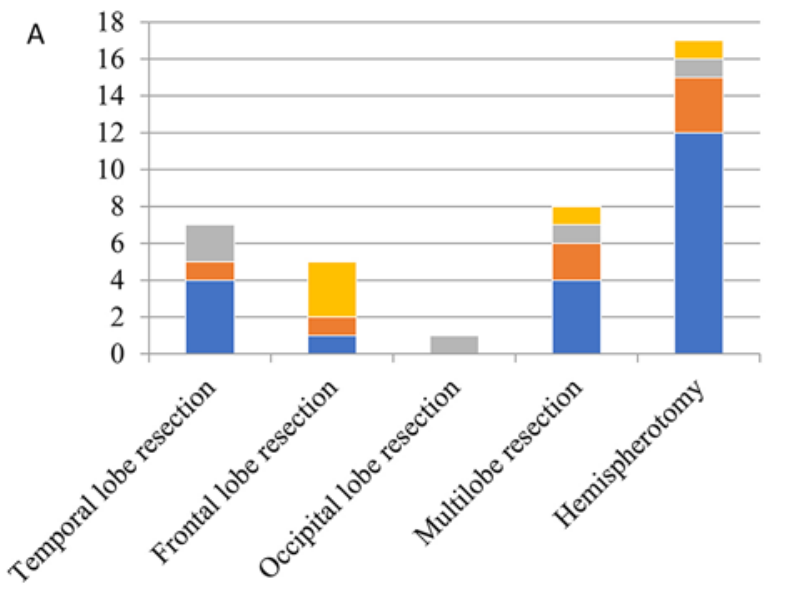

Engel Class IV $\approx$ Engel Class III $=$ Engel Class II $\backsim$ Engel Class I

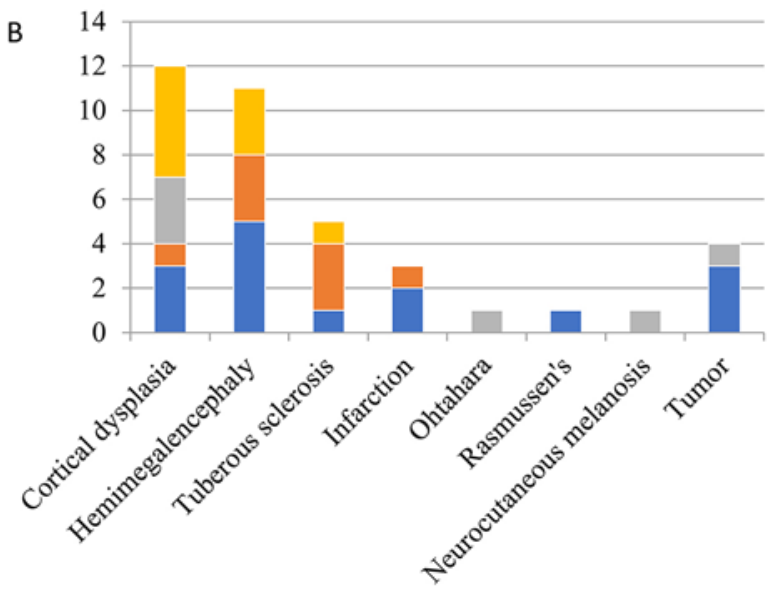

FIG. 2. Long-term seizure outcomes based on surgical technique using Engel classification (A) and diagnosis (B). Figure is available in color online only.

patient with Ohtahara syndrome achieved greater than $90 \%$ reduction in seizure frequency, and the patient with neurocutaneous melanosis $(\mathrm{n}=1)$ achieved $50 \%-90 \%$ reduction in seizure frequency (Fig. 1B).

\section{Long-Term Treatment Outcomes}

To classify long-term postoperative seizure outcomes, the Engel classification was used (Fig. 2). In the hemispherectomy group, 53\% ( $\mathrm{n}=9 / 17)$ of children had Engel class I outcomes at last follow-up, followed by $37.5 \%(\mathrm{n}=$ $3 / 8)$ for the multilobe resection group and $26.7 \%(n=4 / 13)$ for the focal resection group. Within the focal resection cohort, $28.6 \%(\mathrm{n}=2 / 7)$ of patients in the temporal lobe resection group and $20 \%(\mathrm{n}=1 / 5)$ in the frontal lobe resection group achieved Engel class I outcomes, respectively.

At last follow-up, the percentages of patients with Engel class I outcomes for each of the diagnoses were Rasmussen's encephalitis $100 \%(n=1)$, tumors $75 \%(n=3 / 4)$, stroke $33.3 \%(\mathrm{n}=1 / 3)$, hemimegalencephaly $45.4 \%(\mathrm{n}=$ $5 / 11)$, cortical dysplasia $25 \%(\mathrm{n}=3 / 12)$, and tuberous sclerosis $20 \%(n=1 / 5)$. The patients diagnosed with Ohtahara 
syndrome $(\mathrm{n}=1)$ and neurocutaneous melanosis $(\mathrm{n}=1)$ were in Engel class III at last follow-up.

A brief analysis of seizure outcomes based on surgical date indicates a trend toward improved outcomes with later surgeries. There is a myriad of factors that can influence this, including, but not limited to, experience gained, technical advances, and improvements in the perioperative management of epilepsy patients.

\section{Complications and Survival Outcomes}

Perioperative morbidity revealed 4 complications: 2 infections and 1 case each of perioperative stroke and immediate reoperation for seizures. All patients who underwent hemispherectomy or multilobar resections had a prophylactic external ventricular drain placed at the time of operation, and no patients went on to develop late hydrocephalus requiring a shunt. The drain was managed and weaned in standard fashion, and no further specific technical changes dedicated to the management of postoperative hydrocephalus were made. The median seizure-free survival among the children who did not remain seizure free was 8.3 years. The median seizure-free survival was greatest for children in the multilobar group (14.6 years), followed by the hemispherectomy group ( 8.3 years) and the focal resection group ( 7.3 years). Figure 3 shows the individual Kaplan-Meier curves for all children and broken down by surgical technique.

\section{Discussion}

We performed a literature review of papers studying epilepsy surgery in children younger than 3 years. Articles were included in our literature review if they included at least 10 cases in which an infant underwent surgery at or before the age of 3 years with functional outcomes that could be correlated. Data extracted from the articles included the number of cases, mean age at onset of seizure and at time of surgery, diagnosis, surgical technique, surgical outcome, and complications. A total of 13 articles met the inclusion criteria and were included, accounting for 382 cases with an average follow-up duration of 5.2 years. $7,10,13,15,18,21,25,26,28-32$ While this literature search returned a large pooled number of patients, less than $14 \%$ were of the same age demographic as our study, that is, infants with epilepsy operated on before the age of 12 months. The studies that focus on epilepsy surgery in these infant patients are further presented in Table 4 . The strength of this study as the largest case series of infants younger than 12 months operated on for catastrophic epilepsy is that it shows that operative management of these patients can be safe and effective.

\section{Surgical Outcomes}

The percentage of seizure-free outcomes in these series ranged from $47 \%$ to $80 \%$, comparing favorably with our results. Surgical techniques ranged from hemispherectomies to focal resections and/or lobectomies. Within the category of hemispherectomies, there was wide heterogeneity in the specific technical procedure performed, whether it be anatomical, functional, or modified anatomical. Sugimoto et al. showed significantly better seizure outcomes in chil-
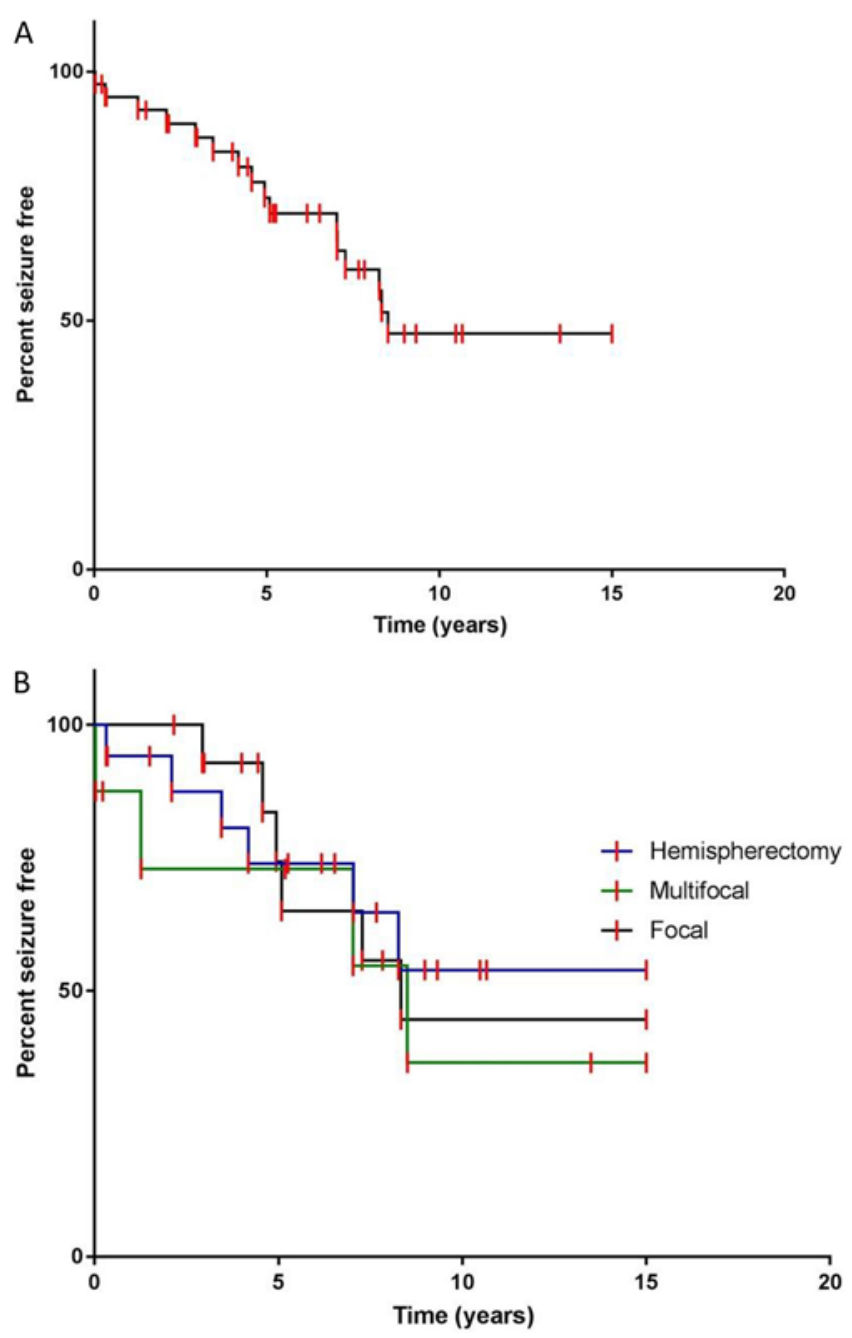

FIG. 3. Kaplan-Meier curve for seizure freedom in all patients $(\mathbf{A})$ and based on surgical technique (B). Figure is available in color online only.

dren who underwent hemispherectomies than those who underwent focal resections. ${ }^{15}$ This correlates with our data, where hemispherectomy patients had better long-term seizure outcomes. However, many of the other studies showed equal outcomes between hemispheric surgeries and focal resections. It is difficult to draw definitive conclusions on whether one type of procedure is superior to the other. In comparison with seizure outcomes of children operated on before the age of 3 years but older than 12 months, there appears to be similar effectiveness and safety.

\section{Developmental Outcomes}

Steinbok et al. reported that $55.3 \%$ of patients had improved developmental outcomes after surgery, although the exact developmental assessment tools used were not indicated. In their cohort, they found a trend toward improved developmental outcomes in children who became seizure free $(60.7 \%)$ compared with those with residual seizures (44.8\%). ${ }^{31}$ Other studies have used the perioperative developmental quotient (DQ) as a marker of change in development after surgery. Loddenkemper et al. showed a 
TABLE 4. Results from literature review on epilepsy surgery in infants and young children

\begin{tabular}{|c|c|c|c|c|c|c|c|c|}
\hline Authors \& Year & $\begin{array}{l}\text { No. of } \\
\text { Patients }\end{array}$ & $\begin{array}{l}\text { Mean } \\
\text { Age at } \\
\text { Sz Onset } \\
\text { (mos) }\end{array}$ & $\begin{array}{l}\text { Mean } \\
\text { Age } \\
\text { at Op } \\
\text { (mos) }\end{array}$ & Surgical Technique & Diagnosis/Pathology & Engel Class & Complications & Other \\
\hline $\begin{array}{l}\text { Kumar et al., } \\
2015^{7^{*}}\end{array}$ & 25 & 1.0 & 4.7 & $\begin{array}{l}\text { 64\% hemispheroto- } \\
\text { my; 34\% FR/L }\end{array}$ & $\begin{array}{l}\text { FCD } 48 \% \text {; HME } 32 \% \text {; } \\
\text { stroke } 8 \%\end{array}$ & | 80\%; ||/||| 8\% & $\begin{array}{l}\text { Hydrocephalus } 20 \% \text {; in- } \\
\text { fection } 4 \% \text {; death } 4 \%\end{array}$ & \\
\hline $\begin{array}{l}\text { Ramantani et al., } \\
2013^{30}\end{array}$ & 30 & 5.0 & 20.0 & $\begin{array}{l}47 \% \text { hemispheroto- } \\
\text { my; } 53 \% \text { FR/L }\end{array}$ & $\begin{array}{l}\text { MCD } 80 \% \text {; tumor } \\
10 \% \text {; stroke } 10 \%\end{array}$ & | 70\%; ||/II| 20\% & $\begin{array}{l}\text { Blood transfusion } 87 \% \\
\text { hydrocephalus } 13 \% \\
\text { neuro deficit } 17 \%\end{array}$ & \\
\hline $\begin{array}{l}\text { Taussig et al., } \\
2012^{32}\end{array}$ & 25 & 5.2 & 23.0 & $100 \% \mathrm{FR}$ & $\begin{array}{l}\text { MCD } 85 \% \text {; stroke } \\
7.7 \% \text {; tumor } 7.7 \%\end{array}$ & $|65 \% ;||/||| 19 \%$ & $\begin{array}{l}\text { Neuro deficit 19\%; sub- } \\
\text { dural collection } 8 \%\end{array}$ & \\
\hline $\begin{array}{l}\text { Dunkley et al., } \\
2011^{26}\end{array}$ & 42 & 5.0 & 20.0 & $\begin{array}{l}64.3 \% \text { hemispherec- } \\
\text { tomy; } 36 \% \text { FR/L }\end{array}$ & $\begin{array}{r}\text { MCD } 74 \% \text {; SW } 12 \% \\
\text { tumor/stroke } 4.7 \%\end{array}$ & | 47\%; ||/||| 43\% & Hydrocephalus $12 \%$ & $\begin{array}{c}\Delta \mathrm{DQ} \\
30 \rightarrow 28\end{array}$ \\
\hline $\begin{array}{l}\text { Gowda et al., } \\
2010^{28 *}\end{array}$ & 15 & 0.07 & 3.97 & $\begin{array}{c}78.5 \% \text { hemispherec- } \\
\text { tomy; } 21.5 \% \text { FR/L }\end{array}$ & $\begin{array}{c}\text { MCD 53.3\%; HME } \\
\text { 40\%; TS } 6.7 \%\end{array}$ & | 53\%; ||/||| 33\% & $\begin{array}{l}\text { Aseptic meningitis } 27 \% \text {; } \\
\text { MCA infarct } 7 \%\end{array}$ & \\
\hline $\begin{array}{l}\text { Steinbok et al., } \\
2009^{31}\end{array}$ & 116 & & 15.8 & $\begin{array}{l}34.5 \% \text { hemispherec- } \\
\text { tomy; } 65.5 \% \text { FR/L }\end{array}$ & $\begin{array}{l}\text { MCD } 29.3 \% \text {; tumors } \\
\text { 19\%; SW } 16.3 \%\end{array}$ & $\mid 62 \%$; ||/||| 23\% & $\begin{array}{l}\text { Infection } 15 \% \text {; aseptic } \\
\text { meningitis } 11 \% \text {; hydro- } \\
\text { cephalus } 6 \%\end{array}$ & \\
\hline $\begin{array}{l}\text { Loddenkemper et } \\
\text { al., } 2007^{29}\end{array}$ & 24 & 12.0 & 14.0 & $\begin{array}{l}58.3 \% \text { hemispherec- } \\
\text { tomy; } 41.7 \% \mathrm{FR} / \mathrm{L}\end{array}$ & $\begin{array}{l}\text { MCD 79\%; tumor } \\
8.3 \% \text {; SW 8.3\% }\end{array}$ & $|71 \% ;||| /|| 29 \%$ & & $\begin{array}{c}\Delta \mathrm{DQ} \\
37 \rightarrow 49\end{array}$ \\
\hline $\begin{array}{l}\text { Lettori et al., } \\
2008^{13^{*}}\end{array}$ & 10 & 0.66 & 9.3 & $\begin{array}{l}100 \% \text { hemispherec- } \\
\text { tomy }\end{array}$ & $\begin{array}{l}\text { West syndrome } 50 \% \\
\text { Ohtahara } 40 \%\end{array}$ & $|60 \% ;||/||| \mid 40 \%$ & $\begin{array}{l}\text { Hydrocephalus } 27 \% \\
\text { hemorrhage } 9 \%\end{array}$ & $\begin{array}{c}\Delta \mathrm{DQ} \\
33 \rightarrow 32.3\end{array}$ \\
\hline $\begin{array}{l}\text { González-Mar- } \\
\text { tínez et al., } 2005^{18}\end{array}$ & 18 & & 10.9 & $\begin{array}{l}100 \% \text { hemispherec- } \\
\text { tomy }\end{array}$ & $\begin{array}{l}\text { HCD 50\%; HME 39\%; } \\
\text { SW 5\% }\end{array}$ & | 67\%; ||/||| 33\% & & \\
\hline $\begin{array}{l}\text { Bittar et al., } \\
2002^{25}\end{array}$ & 11 & 15.5 & 15.0 & $\begin{array}{c}63.6 \% \text { hemispherec- } \\
\text { tomy; } 37.3 \% \text { FR/L }\end{array}$ & $\begin{array}{l}\text { Stroke } 27 \% \text {; HME } \\
\quad 18 \% \text {; tumor } 18 \%\end{array}$ & | 73\%; ||/II| 27\% & & \\
\hline $\begin{array}{l}\text { Sugimoto et al., } \\
1999^{15}\end{array}$ & 23 & 4.7 & 15.3 & $\begin{array}{l}34.3 \% \text { hemispherec- } \\
\text { tomy; } 65.7 \% \text { FR/L }\end{array}$ & $\begin{array}{l}\text { FCD } 52 \% \text {; SW } 21.7 \% \text {; } \\
\text { tumor } 13 \%\end{array}$ & | 52\%; ||/||| 33\% & & \\
\hline $\begin{array}{l}\text { Duchowny et al., } \\
1998^{10}\end{array}$ & 31 & 4.1 & 18.3 & $\begin{array}{l}45.2 \% \text { hemispherec- } \\
\text { tomy; } 51.6 \% \text { FR/L }\end{array}$ & $\begin{array}{l}\text { MCD 68\%; tumor } \\
22.6 \% \text {; stroke } 6.5 \%\end{array}$ & $|61 \% ;||/||| \mid 19 \%$ & Death $6.5 \%$ & \\
\hline $\begin{array}{l}\text { Wyllie et al., } \\
1996^{21}\end{array}$ & 12 & 4.03 & 15.3 & $\begin{array}{l}41.7 \% \text { hemispherec- } \\
\text { tomy; } 58.3 \% \text { FR/L }\end{array}$ & & | 50\%; ||/||| 42\% & Death 8\% & \\
\hline
\end{tabular}

$\mathrm{FCD}$ = focal cortical dysplasia; $\mathrm{FR/L}$ = focal resection/lobectomy; $\mathrm{HCD}=$ hemispheric cortical dysplasia; $\mathrm{HME}$ = hemimegalencephaly; $\mathrm{MCA}=$ middle cerebral artery; $\mathrm{MCD}=$ malformations of cortical development; neuro = neurological; $\mathrm{SW}=$ Sturge-Weber syndrome .

* Series with infants (e.g., patients operated on $<12$ months old).

modest statistically significant improvement in DQ, from 37 to 49 . Preoperatively, 22 of 24 children in their cohort were developmentally delayed, while postoperatively this number was reduced to $18 .{ }^{29}$ They also found that a higher preoperative DQ was correlated with a higher DQ after surgery and showed a statistically significant correlation between younger age at surgery and improvement in DQ. In contrast, studies by Dunkley et al. and Lettori et al. showed no significant perioperative change in $\mathrm{DQ}^{13,26} \mathrm{Ra}-$ mantani et al. showed that $75 \%$ of children remained in the same developmental status after surgery despite a majority (62\%) achieving seizure freedom; the remaining $25 \%$ showed a decrease in development..$^{30}$ There was a high rate of subjective developmental progress among parents of the affected children.

\section{Complications and Mortality}

Perioperative morbidity has been reported in up to $27 \%$ of infants and young children undergoing epilepsy sur- gery. In addition, there was a high need for blood transfusions, up to $87 \%$ in one case series. ${ }^{30}$ No patients in our series required intraoperative blood transfusion. The most commonly reported complications were hydrocephalus, infections (including deep, superficial, or meningitis), and neurological deficit. By comparison, our case series had a relatively low complication rate at $10 \%$. None of the patients in our series went on to develop late hydrocephalus requiring shunting. Two patients in our group experienced a perioperative infection: one patient with hemimegalencephaly and another with cortical dysplasia. Neither of these patients underwent invasive encephalography prior to surgery. Postoperative stroke is a rare complication after epilepsy surgery in infants and is reported at a rate less than $1 \%$, while reoperation rates have ranged up to $45 \% .^{25}$ One infant in our series had an occipital infarct after resection of multilobe cortical dysplasia with disconnection of the occipital and parietal lobes but remained developmentally normal at last follow-up. Mortality rates in epilepsy surgery in infants range from $4 \%$ to $8 \%, 3,7,10$ which 
compares favorably with our series, and we found that survival rates are good among children who do not remain seizure free, with a median survival of 8.3 years.

\section{Surgical Timing}

Our literature review and institutional experience demonstrate that epilepsy surgery in infants and during early childhood is a safe and effective treatment for medically refractory epilepsy. There are theories that postulate the burden of seizure activity on the developing brain during critical phases can have significant, irreversible detriments on developmental outcomes and that definitive treatment should be instituted as soon as possible. Combining our data with the literature on patients operated on before the age of 1 year reveals good surgical outcomes, with seizure freedom rates between $53 \%$ and $80 \%$. Ramantani et al. reported an $87 \%$ perioperative blood transfusion rate in their series, although it is unclear if this disproportionately affected the $23 \%$ of their patients operated on before 1 year of age.$^{30}$ Kumar et al. reported a $20 \%$ hydrocephalus rate, a $4 \%$ infection rate, and a $4 \%$ mortality rate. ${ }^{7}$ In addition, 1 case was discontinued due to high need for blood transfusion. Gowda et al. reported a postoperative course for 15 patients operated on before the age of 6 months that included 4 cases of aseptic meningitis and 1 case of a middle cerebral artery infarct. ${ }^{28}$ Our series of 40 patients operated on when they were younger than 1 year revealed a $10 \%$ complication rate, with 2 infections, 1 stroke, and 1 reoperation. This supports the fact that operating for epilepsy as soon as technically feasible is a safe and viable option.

\section{Limitations}

Our series is limited by the nature of a retrospective series, including selection bias for surgery (only patients who were deemed good candidates for surgery were selected for surgery) and loss of follow-up for some infants. Nevertheless, the follow-up time of nearly 10 years in our series is robust and suggests that surgery for select infants with medically refractory epilepsy is a durable and safe procedure. Additionally, detailed developmental and neuropsychological outcomes for our patients were not assessed. Additional prospective studies evaluating neurodevelopment over time after epilepsy surgery may help predict which etiology will benefit the most from early surgical intervention.

\section{Conclusions}

For catastrophic epilepsy in infants, surgery can be a safe and efficacious procedure with the long-term potential of curing seizures in a significant portion of patients. There is evidence to suggest that earlier intervention to remove the seizure burden from the developing brain at critical phases may improve developmental outcomes. The risks of surgery on infants must be weighed against the potential risks of continued epilepsy, which can include developmental delay, long-term hospitalization, coma, and even death. The use of a multidisciplinary team with expertise in treating infants with these conditions is a prerequisite to optimize efficacy and safety in this frail population.

\section{References}

1. Glauser TA. Following catastrophic epilepsy patients from childhood to adulthood. Epilepsia. 2004;45(suppl 5):23-26.

2. Howard MA, Baraban SC. Catastrophic epilepsies of childhood. Annu Rev Neurosci. 2017;40:149-166.

3. Saneto RP, Wyllie E. Epilepsy surgery in infancy. Semin Pediatr Neurol. 2000;7(3):187-193.

4. Shields WD. Catastrophic epilepsy in childhood. Epilepsia. 2000;41(suppl 2):S2-S6.

5. Arts WFM, Brouwer OF, Peters ACB, et al. Course and prognosis of childhood epilepsy: 5-year follow-up of the Dutch study of epilepsy in childhood. Brain. 2004;127(Pt 8):17741784.

6. Arts WFM, Geerts AT, Brouwer OF, et al. The early prognosis of epilepsy in childhood: the prediction of a poor outcome. The Dutch study of epilepsy in childhood. Epilepsia. 1999;40(6):726-734.

7. Kumar RM, Koh S, Knupp K, et al. Surgery for infants with catastrophic epilepsy: an analysis of complications and efficacy. Childs Nerv Syst. 2015;31(9):1479-1491.

8. Mattson RH, Cramer JA, Collins JF, et al. Comparison of carbamazepine, phenobarbital, phenytoin, and primidone in partial and secondarily generalized tonic-clonic seizures. $N$ Engl J Med. 1985;313(3):145-151.

9. Wirrell E, Wong-Kisiel L, Mandrekar J, Nickels K. Predictors and course of medically intractable epilepsy in young children presenting before 36 months of age: a retrospective, population-based study. Epilepsia. 2012;53(9):1563-1569.

10. Duchowny M, Jayakar P, Resnick T, et al. Epilepsy surgery in the first three years of life. Epilepsia. 1998;39(7):737-743.

11. Kestle J, Connolly M, Cochrane D. Pediatric peri-insular hemispherotomy. Pediatr Neurosurg. 2000;32(1):44-47.

12. Kwan A, Ng WH, Otsubo H, et al. Hemispherectomy for the control of intractable epilepsy in childhood: comparison of 2 surgical techniques in a single institution. Neurosurgery. 2010;67(2)(Suppl Operative):429-436.

13. Lettori D, Battaglia D, Sacco A, et al. Early hemispherectomy in catastrophic epilepsy: a neuro-cognitive and epileptic long-term follow-up. Seizure. 2008;17(1):49-63.

14. Moosa AN, Jehi L, Marashly A, et al. Long-term functional outcomes and their predictors after hemispherectomy in 115 children. Epilepsia. 2013;54(10):1771-1779.

15. Sugimoto T, Otsubo H, Hwang PA, et al. Outcome of epilepsy surgery in the first three years of life. Epilepsia. 1999;40(5):560-565.

16. Basheer SN, Connolly MB, Lautzenhiser A, et al. Hemispheric surgery in children with refractory epilepsy: seizure outcome, complications, and adaptive function. Epilepsia. 2007;48(1):133-140.

17. Dorfer C, Ochi A, Snead OC III, et al. Functional hemispherectomy for catastrophic epilepsy in very young infants: technical considerations and complication avoidance. Childs Nerv Syst. 2015;31(11):2103-2109.

18. González-Martínez JA, Gupta A, Kotagal P, et al. Hemispherectomy for catastrophic epilepsy in infants. Epilepsia. 2005;46(9):1518-1525.

19. Maton B, Jayakar P, Resnick T, et al. Surgery for medically intractable temporal lobe epilepsy during early life. Epilepsia. 2008;49(1):80-87.

20. Honda R, Kaido T, Sugai K, et al. Long-term developmental outcome after early hemispherotomy for hemimegalencephaly in infants with epileptic encephalopathy. Epilepsy Behav. 2013;29(1):30-35.

21. Wyllie E, Comair YG, Kotagal P, et al. Epilepsy surgery in infants. Epilepsia. 1996;37(7):625-637.

22. Bharti N, Batra YK, Kaur H. Paediatric perioperative cardiac arrest and its mortality: database of a 60 -month period from a tertiary care paediatric centre. Eur J Anaesthesiol. 2009;26(6):490-495. 
23. Thudium MO, von Lehe M, Wessling C, et al. Blood loss and body temperature decline during resective pediatric epilepsy surgery: a retrospective analysis: 7AP2-6. Eur J Anaesthesiol. 2014;31:112.

24. Tiret L, Nivoche Y, Hatton F, et al. Complications related to anaesthesia in infants and children. A prospective survey of 40240 anaesthetics. Br J Anaesth. 1988;61(3):263-269.

25. Bittar RG, Rosenfeld JV, Klug GL, et al. Resective surgery in infants and young children with intractable epilepsy. J Clin Neurosci. 2002;9(2):142-146.

26. Dunkley C, Kung J, Scott RC, et al. Epilepsy surgery in children under 3 years. Epilepsy Res. 2011;93(2-3):96-106.

27. Freitag H, Tuxhorn I. Cognitive function in preschool children after epilepsy surgery: rationale for early intervention. Epilepsia. 2005;46(4):561-567.

28. Gowda S, Salazar F, Bingaman WE, et al. Surgery for catastrophic epilepsy in infants 6 months of age and younger. $J$ Neurosurg Pediatr. 2010;5(6):603-607.

29. Loddenkemper T, Holland KD, Stanford LD, et al. Developmental outcome after epilepsy surgery in infancy. Pediatrics. 2007;119(5):930-935.

30. Ramantani G, Kadish NE, Strobl K, et al. Seizure and cognitive outcomes of epilepsy surgery in infancy and early childhood. Eur J Paediatr Neurol. 2013;17(5):498-506.

31. Steinbok P, Gan PY, Connolly MB, et al. Epilepsy surgery in the first 3 years of life: a Canadian survey. Epilepsia. 2009;50(6):1442-1449.
32. Taussig D, Dorfmüller G, Fohlen M, et al. Invasive explorations in children younger than 3 years. Seizure. 2012;21(8):631-638.

\section{Disclosures}

The authors report no conflict of interest concerning the materials or methods used in this study or the findings specified in this paper.

\section{Author Contributions}

Conception and design: Ragheb, Ibrahim, Bhatia. Acquisition of data: Shah, Sur, Achua. Analysis and interpretation of data: Ye, Shah, Sur, Achua, Ibrahim. Drafting the article: Ye, Shah, Sur, Achua, Ibrahim. Critically revising the article: Ragheb, Ye, Shah, Sur, Wang, Ibrahim, Bhatia. Reviewed submitted version of manuscript: Ragheb, Ye, Shah, Sur, Achua, Ibrahim, Bhatia. Approved the final version of the manuscript on behalf of all authors: Ragheb. Statistical analysis: Ragheb, Shah, Sur, Achua, Ibrahim. Administrative/technical/material support: Ragheb, Ibrahim, Bhatia. Study supervision: Ragheb, Bhatia.

\section{Correspondence}

John Ragheb: University of Miami, FL.jragheb@med.miami.edu. 